\title{
Review
}

\section{Methods of Analyzing Microsized Plastics in the Environment}

\author{
Hyunjeong Woo ${ }^{1}$, Kangmin Seo ${ }^{1}$, Yonghyun Choi ${ }^{1}$, Jiwon Kim ${ }^{1}$, Masayoshi Tanaka ${ }^{2}$, Keunheon Lee ${ }^{3}$ (I) \\ and Jonghoon Choi ${ }^{1, *(D)}$ \\ 1 School of Integrative Engineering, Chung-Ang University, Seoul 06974, Korea; \\ hyunjeong1226@gmail.com (H.W.); seopreme96@gmail.com (K.S.); dydgus5057@gmail.com (Y.C.); \\ jackykjw@gmail.com (J.K.) \\ 2 Department of Chemical Science and Engineering, Tokyo Institute of Technology, Tokyo 152-8552, Japan; \\ tanaka.m.bn@m.titech.ac.jp \\ 3 Humas, Daejeon 34224, Korea; humas1@humas.co.kr \\ * Correspondence: nanomed@cau.ac.kr
}

Citation: Woo, H.; Seo, K.; Choi, Y.; Kim, J.; Tanaka, M.; Lee, K.; Choi, J. Methods of Analyzing Microsized Plastics in the Environment. Appl. Sci. 2021, 11, 10640. https://doi.org/ 10.3390/app112210640

Academic Editor: Rajender S. Varma

Received: 26 September 2021

Accepted: 8 November 2021

Published: 11 November 2021

Publisher's Note: MDPI stays neutral with regard to jurisdictional claims in published maps and institutional affiliations.

Copyright: (c) 2021 by the authors. Licensee MDPI, Basel, Switzerland. This article is an open access article distributed under the terms and conditions of the Creative Commons Attribution (CC BY) license (https:// creativecommons.org/licenses/by/ $4.0 /)$.

\begin{abstract}
Microplastics are found in various environments with the increasing use of plastics worldwide. Several methods have been developed for the sampling, extraction, purification, identification, and quantification of microplastics in complex environmental matrices. This study intends to summarize recent research trends on the subject. Large microplastic particles can be sorted manually and identified through chemical analysis; however, sample preparation for small microplastic analysis is usually more difficult. Microplastics are identified by evaluating the physical and chemical properties of plastic particles separated through extraction and washing steps from a mixture of inorganic and organic particles. This identification has a high risk of producing false-positive and false-negative results in the analysis of small microplastics. Currently, a combination of physical (e.g., microscopy), chemical (e.g., spectroscopy), and thermal analyses is widely used. We aim to summarize the best strategies for microplastic analysis by comparing the strengths and limitations of each identification method.
\end{abstract}

Keywords: microplastics; separation; detection; microscopy; spectroscopy

\section{Introduction}

Plastics are resin products that are molded and processed by applying heat or pressure. In general, they refer to synthetic resins which are easy to synthesize and have light but complex properties. Additionally, it is possible to enhance their suitability for their purpose of use through plastic-related chemicals (PRCs), such as whitening agents, plasticizers, antioxidants, and surfactants, which are added during synthesis [1,2]. The usage of plastic and the amount of plastic waste thrown away have rapidly increased because it is easy to transform plastic into various shapes [1,3-5]. In particular, the amount of plastic waste has recently risen due to the use of masks to prevent the spread of COVID19 [6]. Microplastics are also produced during the use of plastic products. The formation of microplastics has also increased because they are also found in discarded waste [7].

Microplastics, synthetic organic polymers with a size of $5 \mathrm{~mm}$ or less, are classified as primary and secondary microplastics. Primary microplastics are those made at the appropriate size from the beginning for use as microplastics, such as those in face wash and beads. Secondary microplastics form after larger pieces of plastic naturally decompose due to UV light, waves, and wind or due to wear or waste while being used [5,8,9]. Once microplastics are introduced into the environment, they are difficult to remove. Plastic undergoes degradation into micro sizes due to physical influences (e.g., wind or rain), chemical influences (e.g., ultraviolet radiation from sunlight or corrosion), and through biodegradation (e.g., microorganisms) mechanisms [10]. Moreover, it is distributed over wide areas by waves and wind because it is light. Microplastics are ubiquitous from near shore areas to the middle of the sea, from sea level to the bottom, and from the subtropical 
seas to the poles $[11,12]$. It has been reported that plankton, which lie on the lowest tropic level in the marine ecosystem, ingest microplastics as food. Plankton are then eaten by predators higher up the food chain. It was confirmed that microplastics were also accumulated in plants, water, and honey $[13,14]$. As such, microplastics accumulated from lower tropic levels eventually accumulate in humans, the highest predator $[15,16]$. Since humans consume both animals and plants, the amount of microplastics accumulating in the body through food is increasing. The toxicity of microplastics accumulating in the body has not yet been clearly reported. However, there are studies that show their tendency to cause chronic inflammation; therefore, we believe that the toxicity of microplastics should be evaluated after further research is conducted on this [17]. Ingested microplastics also reduce in size through the digestive process [18]. In addition, heavy metals and organic pollutants accumulate on the surface of microplastics and move together, increasing environmental pollution [19].

Studies monitoring microplastics require reliable and comparable standardized sampling and analysis methods [20,21]. Additionally, studies on the toxicity and body accumulation of microplastics require appropriate methods for analyzing microplastics qualitatively and quantitatively. However, analytical methods for microplastics are currently in the development stage, and a standardized method has not yet been determined [22].

The procedure for analyzing microplastics from environmental samples consists of extraction, separation, identification, and quantification [23]. It is generally possible to classify large microplastics in size range of $1-5 \mathrm{~mm}$ with the naked eye. However, studying the wide size range of microplastics and their harmful biological effects requires quantification to the smallest possible size, including nanoscale plastics. In addition, it is difficult to organize analysis results through characteristics, such as size, shape, color, and polymer type, because microplastics are produced from various types of plastics synthesized for each purpose. This review focuses on summarizing the technologies developed and currently used for the sampling, extraction, purification, and detection of microplastics in real environmental samples and anticipating the direction of future technologies (Figure 1, Table 1).

Table 1. Summary of technically analyzing results.

\begin{tabular}{|c|c|c|c|c|}
\hline Analysis & Definition & Advantage & Disadvantage & References \\
\hline Microscopy & $\begin{array}{l}\text { Analyze substances using a } \\
\text { microscope. Optical } \\
\text { microscopes to electron } \\
\text { microscopes such as SEM } \\
\text { and TEM are widely used. }\end{array}$ & $\begin{array}{l}\text { Able to directly observe } \\
\text { the surface } \\
\text { Simple sample } \\
\text { preparation }\end{array}$ & $\begin{array}{l}\text { Takes the longest time } \\
\text { to determine } \\
\text { Depending on the } \\
\text { researcher, the result } \\
\text { judgment may vary, } \\
\text { resulting in low accuracy }\end{array}$ & {$[24,25]$} \\
\hline Spectroscopy & $\begin{array}{l}\text { Analyze the surface of a } \\
\text { material using } \\
\text { optical technology }\end{array}$ & $\begin{array}{l}\text { Multiple samples can } \\
\text { be analyzed at once, } \\
\text { and the method } \\
\text { preserves the sample } \\
\text { Existing data library } \\
\text { can be used for analysis }\end{array}$ & $\begin{array}{l}\text { Difficult to discriminate } \\
\text { large amounts of samples } \\
\text { Takes a long time } \\
\text { to identify }\end{array}$ & {$[26,27]$} \\
\hline Thermal analysis & $\begin{array}{l}\text { Analysis using heat based } \\
\text { on the unique physical and } \\
\text { chemical properties of } \\
\text { each substance }\end{array}$ & $\begin{array}{l}\text { A large number of } \\
\text { samples can be } \\
\text { identified at once } \\
\text { Existing data library } \\
\text { can be used for analysis }\end{array}$ & $\begin{array}{c}\text { Samples are } \\
\text { not preserved } \\
\text { Quantitative analysis of } \\
\text { each sample is } \\
\text { not possible }\end{array}$ & {$[28,29]$} \\
\hline Emerging Technology & $\begin{array}{l}\text { Analyze using a new } \\
\text { technology that is } \\
\text { attracting attention instead } \\
\text { of the previously described } \\
\text { analysis methods }\end{array}$ & $\begin{array}{l}\text { Development in the } \\
\text { direction of } \\
\text { complementing the } \\
\text { shortcomings of } \\
\text { existing technologies }\end{array}$ & $\begin{array}{c}\text { Less data } \\
\text { accumulated than } \\
\text { existing technologies }\end{array}$ & {$[30,31]$} \\
\hline
\end{tabular}




\section{Microplastic Analysis}

Microscopy
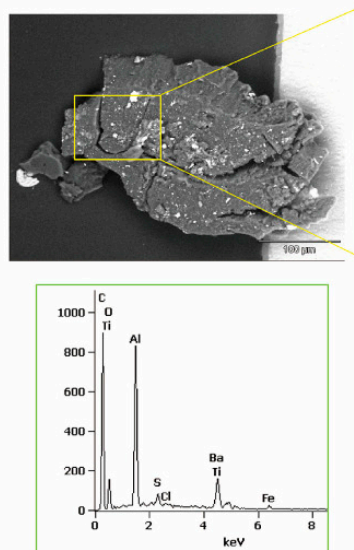

\section{SEM-EDS}

\section{Spectroscopy}
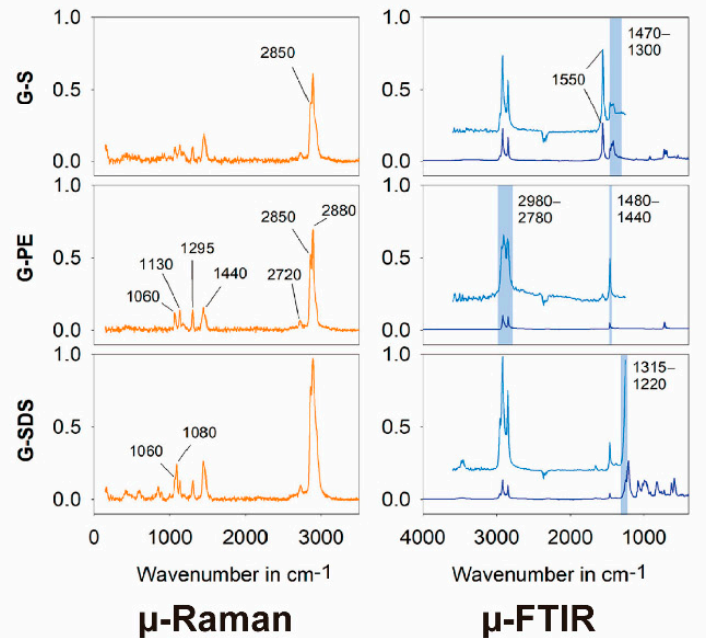

Thermal Analysis

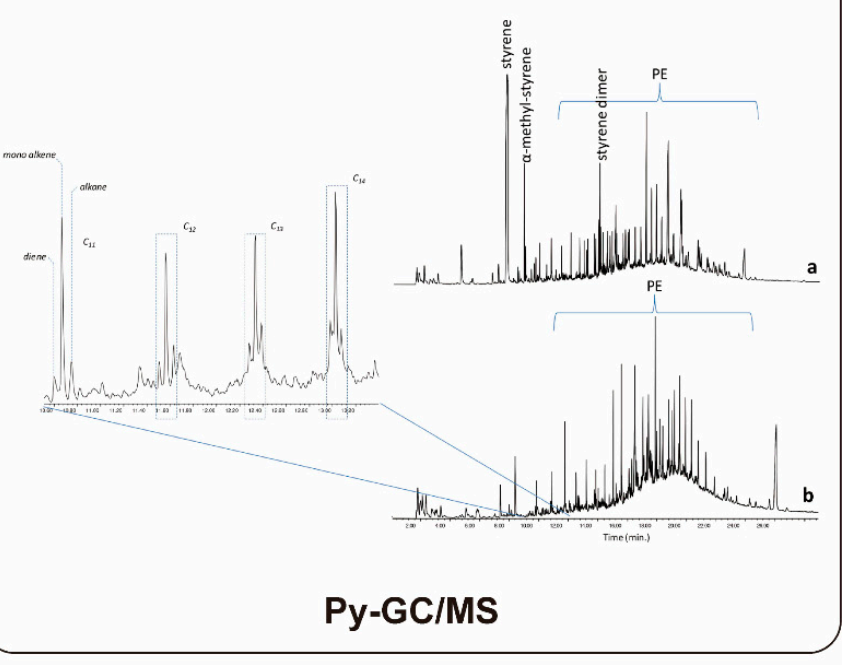

Emerging Tech
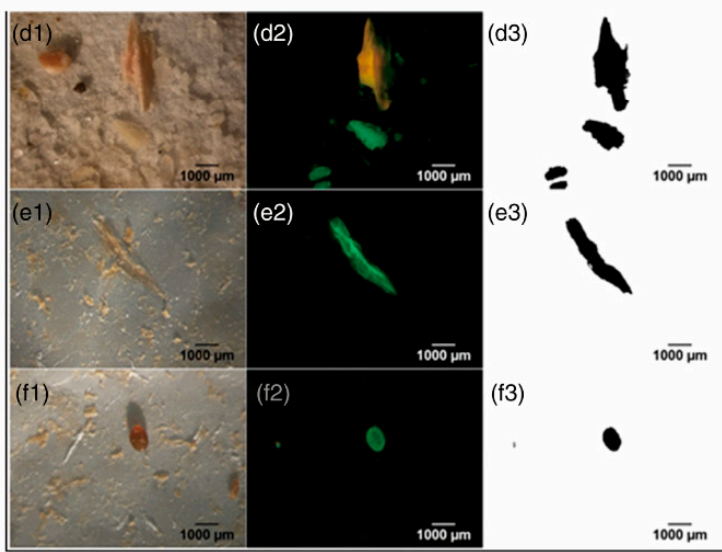

Nile red staining

Figure 1. Four major approaches to analyze microplastics in the environment. Microscopic observation allows the size, shape, and chemical composition of target microplastics to be directly probed. Thermal and spectroscopic analyses allow researchers to understand target plastics' chemical and physical signatures. Emerging technologies, including a simple dye staining method, help to expedite the simultaneous, high-throughput capture of microplastics without using expensive analytical instruments. In Figure, dunes (a), foreshore (b), photographs (d1, e1, f1), Nile Red staining (d2, e2, f2) and the analysis process by Image J program (d3, e3, f3) can be checked. Reprinted with permission from the reference [32-35]. Copyright 2018, 2019, 2020 American Chemical Society. Additionally, copyright 2019 John Wiley and Sons.

Methods for identifying plastics using various techniques such as microscopy, spectroscopy and thermal analysis have been continuously developed (Figure 1, Table 1). Each technology has different characteristics as well as advantages/disadvantages. Microscopy enables the most intuitive identification of results through visual confirmation. Sample preparation is simple but time consuming, and is less accurate than other methods [24,25]. Spectroscopy uses optical principles to analyze the surface of a sample. Multiple samples can be identified at once, and data libraries for each material that have been 
previously accumulated can be used for analysis. In addition, the sample is preserved after analysis, and quantitative analysis such as oxidation of each particle is possible [26]. However, compared to thermal analysis, it is difficult to identify a large number of samples at once [33]. Thermal analysis has the advantage of being able to discriminate larger amounts of samples than the aforementioned microscopy and spectroscopy [28]. However, since the sample is melted using heat, it is not preserved; only qualitative identification is possible and quantitative analysis for each plastic particle is difficult [36]. In other methods using optical principles, organic matter or heavy metals are attached to particle surfaces in samples taken from nature; this may make it difficult to confirm results [36]. In addition, the surface may be affected by $\mathrm{pH}$ after being digested in vivo, which may affect the analysis of results such as FTIR. After dissolving the sample, it is distinguished through the peak for each molecule, and so the influence of this part is relatively small [37]. In order to compensate for the shortcomings of each technology and to use only their advantages for analysis, several technologies are sometimes used in combination. The TGA-FTIR-GC-MS described above is a representative example [38].

Among the various analysis methods, an appropriate analysis method should be selected considering the information that needs to be obtained from samples the priority of each type of data.

\section{Microscopy Analyses}

\subsection{Microscopy}

Light microscopy is widely used to identify microplastics in the range of several hundred micrometers. Microplastics generally have no luster and are identified based on physical reaction properties, such as specific elasticity or hardness [24]. Furthermore, microplastics usually take the form of fibers, fragments, and beads in the environment [39]. About $70 \%$ of microplastic samples are transparent [40]. Colored plastics to which dye is added during synthesis can be easily identified with an optical microscope [41]. It is difficult to characterize plastic particles in the size range below $100 \mu \mathrm{m}$ that are colorless or non-obvious in shape. Furthermore, the poor separation of sample particles can interfere with the microscopic identification of microplastics. In addition, sediments and biological materials that are not completely removed by chemical decomposition make it difficult to observe microplastics under a microscope. Previous studies have shown that the rate of microscopic misidentification of plastic-like particles is more than about $20 \%$ and more than $70 \%$ for transparent particles. Synthetic and natural fibers constitute similar particles with interfering factors, making it difficult to distinguish them under a microscope alone. "Destructive tests" have been conducted to identify particles, but cotton fibers are often misidentified as plastic. Studies have used a method to identify such particles to compensate for this; particles are put in contact with a heated needle, and the plastic particles melt under such treatment $[42,43]$.

In the plastic synthesis and textile industries, whitening agents are the most used plastic additives. Since whitening agents generally have fluorescence, the detection of plastics can be performed through a fluorescence microscope. However, whitening agents are also added to paper. Detection errors may still occur because there are substances with a characteristic of self-fluorescence among minerals [41].

\subsection{Electron Microscopy—SEM/TEM}

Scanning electron microscopy (SEM) can provide very sharp, high-magnification images even for very small particles, such as nanoplastics [44]. The texture of the particle surface, which can be confirmed through high-resolution images, makes it easy to distinguish between organic particles and microplastics [45]. Transmission electron microscopy (TEM) is also used for the identification of microplastics. Visual identification of microplastics through TEM may vary depending on the user; nonetheless, errors can be reduced by cross-validating results from multiple users through a well-established protocol. Further analysis using energy-dispersive X-ray spectroscopy (EDS) provides the elemental 
composition of the object in question. Additionally, components of additives, such as $\mathrm{Al}$, $\mathrm{Ca}, \mathrm{Mg}, \mathrm{Na}$, and $\mathrm{Si}$, or antioxidants in microplastics are captured as markers and used for identification using EDS [25,32]. Determining the surface elemental composition of a particle can be useful for identifying carbon-rich plastics from inorganic particles [39,46]. However, SEM and TEM limit the number of samples that can be processed because the equipment is expensive, and sample preparation and inspection require significant time and effort.

\subsection{Polarizing Microscopy}

Polarized light microscopy has been successfully used to identify polyethylene (PE) particles in toxicity experiments [47]. The crystal structure within the plastic can affect the transmission of polarized light that can be measured [48]. The degree of crystallinity depends on the type of polymer; it varies even within the same polymer depending on the manufacturing process. However, microplastic samples must be thin to allow sufficient polarized light to pass through. This method cannot be used for opaque microplastic samples.

\section{Spectroscopy Analyses}

\subsection{Fourier Transform Infrared Spectroscopy}

Fourier transform infrared (FTIR) spectroscopy provides information about the specific chemical bonding of particles. Carbon-based polymers can be easily identified using this method. The chemical structure of plastics with different bonding configurations creates a unique spectrum that distinguishes them from other organic and inorganic particles [3,49]. Furthermore, plastics can be identified through well-established polymer spectral libraries [50,51]. Using infrared (IR) spectra to organize information for each plastic prevents the false-positive quantification of non-plastic particles and reduces the chance of overlooking plastic particles without a specific color or texture. Additionally, identification using FTIR reveals the polymer composition, which can provide clues to the origin and mechanism of occurrence of the sample [52]. The composition of oxygen bonds (e.g., carbonyl groups) in the IR spectrum can also provide information on the oxidation state of microplastics [26,53].

Microplastics are easier to identify using micro-FTIR, which has both features, which together allow the microscopic observation of microscopically sized plastic-like particles prior to spectroscopic confirmation on a single platform [24]. Moreover, transmittance, reflectance, and attenuated total reflectance (ATR) modes can be used in the FTIR analysis of microplastics [42]. The reflectance and ATR modes do not require sample preparation steps for thick and opaque microplastics, unlike the transmission mode. In addition, the ATR mode can generate stable spectra on irregular microplastic surfaces. Theoretically, it is possible to detect microplastics as small as the diameter of the ATR probe's IR beam aperture (e.g., $10 \mu \mathrm{m}$ ). Currently, micro-ATR-FTIR is useful for identifying microplastics in environmental samples, complementing the two functions of microscopic identification of plastic-like particles and spectroscopy of subsequent chemical identification [24]. However, it is generally difficult to obtain a clear spectrum that can be accurately identified for microplastics of size less than $50 \mu \mathrm{m}$. Additionally, the pressure generated by the ATR probe can damage fragile microplastics because ATR-FTIR measurement is a form of surface contact analysis [37]. Small plastic particles can be difficult to detect due to adhesion to or electrostatic interactions with the probe tip. Moreover, the ATR mode takes a long time to identify each particle separately. Micro-FTIR instruments are expensive, and using ATR probes to identify individual plastic-like particle is time consuming. Microplastics in environmental samples are usually weathered, often have complex chemical structures, and sometimes exist as composite materials. Therefore, skilled operators must obtain a clear spectrum and interpret it accurately. Moreover, when using a library, it is recommended to register the spectrum of surfactants, such as sodium stearate and sodium dodecyl sulfate (SDS), which can be confused with plastic, in the FTIR library together to reduce the probability of false positives [33]. Pretreating the sample to purify it may be 
required to use FTIR, because there are many reports indicating that heavy metals and microorganisms are adsorbed on the surface of plastics [51,54,55].

It is possible to simultaneously acquire FTIR spectra for multiple microplastics in multiple pixel arrays besides general FTIR when using a focal plane array (FPA) detector $[56,57]$. Independent IR spectra can be obtained for each pixel, which can be used to distinguish small microplastic fibers and fragments [55,58].

The FPA detector takes a long time and utilizes the library, but errors may occur because there are not enough library data [59]. Additionally, further research is needed because PRCs, such as plasticizers, antioxidants, ink components, and adhesive from labels, can affect the FTIR results [60].

\subsection{Raman Spectroscopy}

In Raman spectroscopy, when an object is irradiated with a laser beam, a unique spectrum for each polymer is generated because the frequency of the backscattered light varies depending on the molecular structure and atoms present in the target. Moreover, Raman spectroscopy identifies plastics and provides a polymer composition profile for each sample, similar to FTIR [33]. It can be used to interpret the obtained results through data libraries and algorithms [61]. Raman spectroscopy is similar to the FTIR method in terms of the combination of non-destructive chemical analysis and microscopy [27]. Microplastics as small as a few micrometers in size can be identified because of the smaller diameter of the laser beam in Raman spectroscopy than FTIR. Non-contact analysis with Raman spectroscopy offers the advantage of preserving the microplastic sample before and after analysis for possible further analysis. However, the differences in the responses and spectra of microplastics between FTIR and Raman spectroscopy may make it more difficult to interpret the results of each method in identifying complex microplastics. It is difficult to identify the target polymer type using Raman spectroscopy because the Raman signal is sensitive to additives and pigment chemicals in microplastics [36]. In addition, errors may occur due to the surface curvature of worn microplastics. It also has similar disadvantages to FTIR: it has a high price and requires expertise for analysis.

In micro-Raman spectroscopy, the identification of material differences is possible only for materials for which an appropriate Raman reference spectrum is provided in the database, and the possibility of confusion between materials has been input in advance. PE is a substance that can be confused with sodium stearate or SDS; it may be difficult to identify the target microplastic, and so the possibility of false positives should be considered [33].

\section{Thermal Analyses}

Thermal analysis techniques, which measure changes in the physical and chemical properties of polymers with thermal stability, have been tested recently to identify microplastics. These techniques are based on the identification of polymers in the degradation products of the sample.

\subsection{Differential Scanning Calorimetry}

Differential scanning calorimetry (DSC) is a useful method to study thermal properties. It shows the changes in dissolution, crystallization, transition temperatures, and corresponding enthalpy and entropy to confirm the physical properties of polymers [62] Since each plastic product has different properties in DSC, it can be used to identify polymer types [28]. However, there are limitations due to overlapping peaks when DSC identifies microplastics with similar melting points [63]. It can only be used to identify certain primary microplastics, such as PE and PP [64].

\subsection{Thermogravimetric Analysis}

Another thermal analysis method is thermogravimetric analysis (TGA). This method confirms the qualitative and quantitative information of the sample by observing the depen- 
dence on time and temperature by measuring the weight loss of the sample while it is heated at a specific rate under preset atmospheric and temperature conditions [65]. Previous studies combined TGA and DSC for the analysis of microplastics in wastewater. However, only PE and polypropylene (PP) were clearly identifiable in these studies. Polyvinyl chloride (PVC), polyamide (PA), and polyester (PES) were not identified. When overlapping phase transition signals occur, such as those of polyethylene terephthalate (PET) and polyurethane (PU), it is difficult to distinguish them $[66,67]$.

\subsection{Pyrolysis-Gas Chromatography Mass Spectrometry}

Pyrolysis-gas chromatography mass spectrometry (Py-GC-MS) is another method for analyzing pyrolyzed gases in polymers [34]. A pyrogram obtained from a sample can be compared to the results of a known polymer standard to determine whether it is plastic. Relatively few plastic (particle) samples (e.g., 0.35-7 mg) are pyrolyzed at a higher temperature than those used in TGA (e.g., $700{ }^{\circ} \mathrm{C}$ ); they are then separated and analyzed using GC-MS [43]. Bulk analysis of sediment and suspended solid particles indicates the presence of PVC, PS, polyvinyl acetate (PVA), poly(acrylonitrile butadiene styrene) (ABS), and styrene butadiene rubber (SBR). However, this method can only identify polystyrene (PS) derivatives, not all microplastics. Further studies are needed to define molecular markers for other types of plastics [25].

\subsection{Complementary Use of Thermal Methods}

Thermal analysis provides an alternative to spectroscopy for the chemical identification of specific polymer types. However, subsequent analysis of microplastic samples is impossible because thermal analysis is a destructive method. The strengths of each method are gathered, and several analysis instruments are used in combination to compensate for each of their shortcomings. Bulk samples can be analyzed by thermal analysis combined with GC-MS to provide total microplastic concentration data by weight [64]. TGA-FTIRGC-MS monitors microplastics in real time and enables both qualitative and quantitative analyses, unlike the existing TGA-FTIR that monitors in real time and only allows qualitative analysis. In addition, thermal decomposition products can be precisely inspected by adding a mass spectrometry step. This helps to overcome the limitations of TGA-FTIR in terms of the polymer types that can be identified; consequently, various polymers (PE, PP, PS, PVC) can be distinguished [29]. In TGA thermal extraction and desorption (TED)-GCMS, a sample can be qualitatively and quantitatively analyzed through TED-GC-MS after TGA analysis is performed. This method can analyze the total microplastic content in large samples, including microplastics of $5 \mu \mathrm{m}$ or less, which are difficult to analyze with FTIR or Raman spectroscopy. The extraction process can be optimized by changing the gas flow and heating rate. This analytical method allows the pyrolysis products to enter the solid phase adsorber, unlike py-GC-MS or TGA-FTIR-GC-MS, where the pyrolysis products move through capillaries. The possibility of clogging the passage between the TGA and the analyzer is minimized because it is first trapped and then separated and extracted [38].

The amount of sample that can be used for analysis is about 200 times that of a sample used in general py-GC-MS. While TED-GC-MS can accommodate up to several tens of milligrams, py-GC-MS is usually limited to a few milligrams [68]. However, information regarding the number, size, and shape of microplastics in thermal analysis is not provided with bulk analysis [69]. Nevertheless, it also has the advantage of being more useful for the identification of smaller-sized microplastics and nanosized plastics because it is independent of the size and shape of the microplastic. This method still requires much more time and effort in instrument execution and data processing than FTIR and Raman spectroscopy [70].

\section{Emerging Technologies}

Approaches produced through the development of new analytical instruments and the combination of new detection technologies with existing instruments are expected to 
solve the current difficulties in microplastic identification. The limit in detectable size is one of the challenges that needs to be addressed in microplastic analyses. The minimum detectable size limit for current analytical methods is a few micrometers. Smaller plastic particles induce greater toxic effects, increasing the need to determine the existence, distribution, fate, and toxicity of nanoscale plastics. Therefore, sampling, extraction, purification, and concentration techniques for nanoplastics should be developed along with new identification methods.

\subsection{Atomic Force Microscopy (AFM)-IR, AFM-Raman}

AFM combined with IR or Raman spectroscopy is a potential candidate for the analysis of nanoplastics. AFM can provide images with nanometer resolution, and AFM probes can operate in both contact and non-contact modes with objects. Furthermore, IR or Raman spectroscopy combined with AFM can reveal the chemical structure of the target plastic [71]. The thermal expansion of the sample due to IR absorption causes the AFM cantilever to vibrate, such that the ring-down pattern is analyzed by Fourier transform to extract the frequency and amplitude of the vibration [72]. Moreover, AFM-IR can simultaneously obtain an image with a spatial resolution of 50-100 $\mathrm{nm}$ and the IR absorption spectrum of the target. In previous studies, AFM and IR spectra of $100 \mathrm{~nm}$ PS beads were successfully acquired. However, finding a single nanoscale plastic particle target to focus on with AFM-IR in an unknown sample is difficult and time consuming.

One of the time-consuming analytical steps in conventional microplastic analysis methods is the manual search for plastic particles. The time required for this process depends on the efficiency of removing inorganic and organic particles in the separation and purification steps in the pretreatment. Manual identification can miss hard-to-recognize plastic particles, especially small, transparent particles. Automated FTIR/Raman mapping or particle tracking using Raman spectroscopy can address these issues; however, it requires expensive instruments that not all microplastics research laboratories can afford.

\subsection{Nile Red Staining of Plastics}

A simple staining method is an alternative to solving the problem of small and transparent particles. Oil red EGN, Eosin B, Hostasol Yellow 3G, and Rose Bengal have been tried, but their practical use is limited [73]. In comparison, Nile red (9-diethylamino$5 \mathrm{H}$-benzo $[\alpha]$ phenoxazine-5-one) is a useful fluorescent dye for selectively dyeing highly hydrophobic microplastics. It is commonly used to stain biologically neutral lipids. Nile red specifically binds to neutral lipids and shows strong fluorescence only in a hydrophobic environment. Nile red staining has a short staining time (10-30 $\mathrm{min}$ ) and high recovery efficiency (up to $96 \%$ ); furthermore, short washing with bleach is performed as required. This is effective for identifying hidden microplastics and provides a useful step before further spectroscopic analysis $[30,35]$. Spectral identification of the same particle can be confirmed immediately after fluorescence microscopy by installing a fluorescence filter on the FTIR microscope. The combination of fluorescence microscopy and FTIR confirmation after Nile red staining can reduce the likelihood of missing microplastics in in situ sample identification [74]. Moreover, it also reduces the time required to identify all plastic-like particles compared to using spectroscopy alone [75].

One of the major limitations when applying Nile red staining to in situ samples is the possibility of co-staining natural organic materials. Therefore, it is important to remove natural lipids and organic matter from the sample prior to Nile red staining. Removing organic matter in the pretreatment step takes a long time, and complete removal is difficult. To overcome this, organic matter removal using $\mathrm{H}_{2} \mathrm{O}_{2}$ or a density separation method using, for example, Fenton reagent or $\mathrm{NaCl}$, has also been attempted; however, its effectiveness is limited because plastics have various densities [57,76,77]. 


\subsection{Near IR Spectra Analysis Method}

A microplastic analysis method using near IR (NIR) spectroscopy has also been tried. FTIR analyzes the spectrum between 600 and $4000 \mathrm{~cm}^{-1}$, but NIR analyzes the spectrum over $4000-15,000 \mathrm{~cm}^{-1}$ [78]. NIR spectra are generally analyzed based on vibration combinations of molecular vibrations of $\mathrm{X}-\mathrm{H}$, such as $\mathrm{C}-\mathrm{H}, \mathrm{O}-\mathrm{H}$, and $\mathrm{N}-\mathrm{H}$. Furthermore, NIR analysis is not sensitive, and it is difficult to use it for quantitative analysis. However, it can classify and analyze a large number of plastic samples within a short timeframe. Therefore, it is a more desirable analysis method to use when determining the type rather than the amount of a sample [79].

\subsection{Vis-NIR Measurement}

Vis-NIR spectroscopy measures the amount of light reflected from the surface of the sample within the wavelength range of 350-2500 $\mathrm{nm}$ to determine the reflectance for each wavelength. This analysis method can be used to quantify microplastics because it relates to the chemical composition of the sample [80]. There is an open vis-NIR spectral data library for various plastics commonly found in the environment, which can be used to identify microplastics such as low-density polyethylene (LDPE), PET, and PVC [31]. However, organic particles can still be mistakenly identified as plastic because it is a visual identification method; therefore, it is necessary to rely on human judgment.

\subsection{Nano Thermal Analysis}

Nano thermal analysis (nano-TA), a method of generating AFM images using nanoTA probes, is a local thermal analysis technique combined with high spatial resolution. Through this, an understanding of the thermal behavior of materials can be obtained with a spatial resolution of less than $100 \mathrm{~nm}$. In nano-TA analysis, the probe moves to a fixed point on the sample surface when a point of interest is selected. The probe is very sensitive to the stiffness (hardness) of the microplastic. The tip heats up at a constant rate over time but stops heating when the sample surface reaches its glass transition temperature. It is mainly used to study the nanoscale surface properties of microplastics and to measure the glass transition temperature because the sample softens during phase inversion. Moreover, it is a method by which the probe penetrates the sample [81].

Recently, a study on the effect of the characteristics of $\mathrm{TiO}_{2}$-dyed microplastics on the aging process and the properties of microplastics affected by the advanced oxidation process was conducted using nano-TA [72,81]. The nano-TA analysis of microplastics provides information on the thermal properties of individual regions, such as glass temperature, which is useful in understanding the chemical composition and physical state of each region of microplastics.

Semi-crystalline polymers of polycaprolactone (PCL), LDPE, polyoxymethylene (POM), PET, PS, polymethyl methacrylate (PMMA), polycarbonate (PC), and the like, and the phase transition temperature for amorphous polymers, have also been studied using the nano-TA analysis method [82].

\section{Perspectives and Outlook}

Various combinations of microplastic analysis methods will help to identify microplastics in complex environmental matrices. As the size of microplastics decreases, it takes longer to identify them. However, there is an increasing need for sub-micron analysis to assess the risks and impacts of microplastics to ecology and human health. As the demand for microplastic contamination monitoring increases, it will be necessary to improve existing methods and develop new methodologies to reduce identification time and effort. Moreover, it will also be important to develop reliable and practical identification methods for detecting and quantifying nanoplastics in environmental samples. A fully or semiautomated analysis method that can integrate image analysis-based methods to obtain the physical properties (such as size and shape) of microplastics and chemical analysis to identify the plastic components should be developed in the future. Additionally, environmental 
pollution caused by synthetic cellulose fibers called viscose in Europe and rayon in the USA is proceeding very similarly to microplastics $[83,84]$. Therefore, this should also be considered when research on microplastics is in progress $[85,86]$. In order not to confuse microplastics with materials that are similar, attention should also be paid to the features that distinguish them. Additionally, research should continue to identify and isolate microplastics from environmental samples through the introduction and development of new dyeing methods, nanotechnology, and analytical techniques.

Author Contributions: Supervision, K.L. and J.C.; Writing-Original Draft Preparation, H.W. and K.S.; Project Administration, Y.C.; Writing-Review and Editing, J.K., M.T. and J.C.; Resources, M.T., K.L. and J.C. All authors have read and agreed to the published version of the manuscript.

Funding: This research was supported by the Chung-Ang University Graduate Research Scholarship in 2020 (J.K.). This work was supported by the Korea Environment Industry and Technology Institute (KEITI), funded by the Korea Ministry of Environment (MOE) (No. 2020003110003). This work was also supported by National Research Foundation of Korea (NRF) grants funded by the Korea government (MSIT) (No. 2020R1A5A1018052).

Institutional Review Board Statement: Not applicable.

Informed Consent Statement: Not applicable.

Data Availability Statement: Not applicable.

Conflicts of Interest: The authors declare no conflict of interest.

\section{References}

1. Mason, S.A.; Welch, V.G.; Neratko, J. Synthetic Polymer Contamination in Bottled Water. Front Chem. 2018, 6, 407. [CrossRef]

2. Wright, R.J.; Bosch, R.; Gibson, M.I.; Christie-Oleza, J.A. Plasticizer Degradation by Marine Bacterial Isolates: A Proteogenomic and Metabolomic Characterization. Environ. Sci. Technol. 2020, 54, 2244-2256. [CrossRef]

3. Garaba, S.P.; Dierssen, H.M. An airborne remote sensing case study of synthetic hydrocarbon detection using short wave infrared absorption features identified from marine-harvested macro- and microplastics. Remote. Sens. Environ. 2018, 205, 224-235. [CrossRef]

4. Sorensen, R.M.; Jovanovic, B. From nanoplastic to microplastic: A bibliometric analysis on the presence of plastic particles in the environment. Mar. Pollut. Bull. 2021, 163, 111926. [CrossRef] [PubMed]

5. Conti, I.; Simioni, C.; Varano, G.; Brenna, C.; Costanzi, E.; Neri, L.M. Legislation to limit the environmental plastic and microplastic pollution and their influence on human exposure. Environ. Pollut. 2021, 288, 117708. [CrossRef] [PubMed]

6. Jung, S.; Lee, S.; Dou, X.; Kwon, E.E. Valorization of disposable COVID-19 mask through the thermo-chemical process. Chem. Eng. J. 2021, 405, 126658. [CrossRef] [PubMed]

7. Chowdhury, H.; Chowdhury, T.; Sait, S.M. Estimating marine plastic pollution from COVID-19 face masks in coastal regions. Mar. Pollut. Bull. 2021, 168, 112419. [CrossRef]

8. Wicaksono, E.A.; Werorilangi, S.; Tahir, A. The influence of weirs on microplastic fate in the riverine environment (case study: Jeneberang River, Makassar City, Indonesia). IOP Conf. Ser. Earth Environ. Sci. 2021, 763, 012054. [CrossRef]

9. Ma, J.; Zhao, J.; Zhu, Z.; Li, L.; Yu, F. Effect of microplastic size on the adsorption behavior and mechanism of triclosan on polyvinyl chloride. Environ. Pollut. 2019, 254, 113104. [CrossRef]

10. Abbasi, S.; Soltani, N.; Keshavarzi, B.; Moore, F.; Turner, A.; Hassanaghaei, M. Microplastics in different tissues of fish and prawn from the Musa Estuary, Persian Gulf. Chemosphere 2018, 205, 80-87. [CrossRef] [PubMed]

11. Wang, S.; Chen, H.; Zhou, X.; Tian, Y.; Lin, C.; Wang, W.; Zhou, K.; Zhang, Y.; Lin, H. Microplastic abundance, distribution and composition in the mid-west Pacific Ocean. Environ. Pollut. 2020, 264, 114125. [CrossRef]

12. Wang, D.; Su, L.; Ruan, H.D.; Chen, J.; Lu, J.; Lee, C.H.; Jiang, S.Y. Quantitative and qualitative determination of microplastics in oyster, seawater and sediment from the coastal areas in Zhuhai, China. Mar. Pollut. Bull. 2021, 164, 112000. [CrossRef] [PubMed]

13. Welle, F.; Franz, R. Microplastic in bottled natural mineral water - literature review and considerations on exposure and risk assessment. Food Addit. Contam. Part A Chem. Anal. Control. Expo. Risk Assess 2018, 35, 2482-2492. [CrossRef] [PubMed]

14. Weis, J.S. Aquatic Microplastic Research-A Critique and Suggestions for the Future. Water 2020, 12, 1475. [CrossRef]

15. Albano, M.; Panarello, G.; Di Paola, D.; Capparucci, F.; Crupi, R.; Gugliandolo, E.; Spanò, N.; Capillo, G.; Savoca, S. The Influence of Polystyrene Microspheres Abundance on Development and Feeding Behavior of Artemia salina (Linnaeus, 1758). Appl. Sci. 2021, 11, 3352. [CrossRef]

16. Savoca, S.; Bottari, T.; Fazio, E.; Bonsignore, M.; Mancuso, M.; Luna, G.M.; Romeo, T.; D’Urso, L.; Capillo, G.; Panarello, G.; et al. Plastics occurrence in juveniles of Engraulis encrasicolus and Sardina pilchardus in the Southern Tyrrhenian Sea. Sci. Total Environ. 2020, 718, 137457. [CrossRef] [PubMed]

17. Song, J.; Na, J.; An, D.; Jung, J. Role of benzophenone-3 additive in chronic toxicity of polyethylene microplastic fragments to Daphnia magna. Sci. Total Environ. 2021, 800, 149638. [CrossRef] 
18. Dawson, A.L.; Kawaguchi, S.; King, C.K.; Townsend, K.A.; King, R.; Huston, W.M.; Bengtson Nash, S.M. Turning microplastics into nanoplastics through digestive fragmentation by Antarctic krill. Nat. Commun. 2018, 9, 1001. [CrossRef] [PubMed]

19. Li, Y.; Li, M.; Li, Z.; Yang, L.; Liu, X. Effects of particle size and solution chemistry on Triclosan sorption on polystyrene microplastic. Chemosphere 2019, 231, 308-314. [CrossRef]

20. Muller, Y.K.; Wernicke, T.; Pittroff, M.; Witzig, C.S.; Storck, F.R.; Klinger, J.; Zumbulte, N. Microplastic analysis-are we measuring the same? Results on the first global comparative study for microplastic analysis in a water sample. Anal. Bioanal. Chem. 2020, 412, 555-560. [CrossRef]

21. Galgani, F.; Hanke, G.; Werner, S.; De Vrees, L. Marine litter within the European Marine Strategy Framework Directive. ICES J. Mar. Sci. 2013, 70, 1055-1064. [CrossRef]

22. Uddin, S.; Fowler, S.W.; Saeed, T. Microplastic particles in the Persian/Arabian Gulf - A review on sampling and identification. Mar. Pollut. Bull. 2020, 154, 111100. [CrossRef] [PubMed]

23. Zarfl, C. Promising techniques and open challenges for microplastic identification and quantification in environmental matrices. Anal. Bioanal. Chem. 2019, 411, 3743-3756. [CrossRef]

24. Morgado, V.; Gomes, L.; Bettencourt da Silva, R.J.N.; Palma, C. Validated spreadsheet for the identification of PE, PET, PP and PS microplastics by micro-ATR-FTIR spectra with known uncertainty. Talanta 2021, 234, 122624. [CrossRef] [PubMed]

25. Watteau, F.; Dignac, M.-F.; Bouchard, A.; Revallier, A.; Houot, S. Microplastic Detection in Soil Amended With Municipal Solid Waste Composts as Revealed by Transmission Electronic Microscopy and Pyrolysis/GC/MS. Front. Sustain. Food Syst. 2018, 2, 81. [CrossRef]

26. Zhou, L.; Wang, T.; Qu, G.; Jia, H.; Zhu, L. Probing the aging processes and mechanisms of microplastic under simulated multiple actions generated by discharge plasma. J. Hazard. Mater. 2020, 398, 122956. [CrossRef] [PubMed]

27. Kniggendorf, A.K.; Wetzel, C.; Roth, B. Microplastics Detection in Streaming Tap Water with Raman Spectroscopy. Sensors 2019, 19, 1839. [CrossRef]

28. Zainuddin, Z.; Syuhada. Study of Analysis Method on Microplastic Identification in Bottled Drinking Water. Macromol. Symp. 2020, 391, 1900195. [CrossRef]

29. Liu, Y.; Li, R.; Yu, J.; Ni, F.; Sheng, Y.; Scircle, A.; Cizdziel, J.V.; Zhou, Y. Separation and identification of microplastics in marine organisms by TGA-FTIR-GC/MS: A case study of mussels from coastal China. Environ. Pollut. 2021, 272, 115946. [CrossRef] [PubMed]

30. Erni-Cassola, G.; Gibson, M.I.; Thompson, R.C.; Christie-Oleza, J.A. Lost, but Found with Nile Red: A Novel Method for Detecting and Quantifying Small Microplastics (1 mm to $20 \mathrm{mum}$ ) in Environmental Samples. Environ. Sci. Technol. 2017, 51, 13641-13648 [CrossRef] [PubMed]

31. Garaba, S.; Dierssen, H. Spectral reference library of 11 types of virgin plastic pellets common in marine plastic debris. Data Set 2017. Available online: https:/ / ecosis.org/package/spectral-reference-library-of-11-types-of-virgin-plastic-pellets-commonin-marine-plastic-debris (accessed on 25 September 2021).

32. Wagner, J.; Wang, Z.M.; Ghosal, S.; Murphy, M.; Wall, S.; Cook, A.M.; Robberson, W.; Allen, H. Nondestructive Extraction and Identification of Microplastics from Freshwater Sport Fish Stomachs. Environ. Sci. Technol. 2019, 53, 14496-14506. [CrossRef]

33. Witzig, C.S.; Foldi, C.; Worle, K.; Habermehl, P.; Pittroff, M.; Muller, Y.K.; Lauschke, T.; Fiener, P.; Dierkes, G.; Freier, K.P.; et al. When Good Intentions Go Bad-False Positive Microplastic Detection Caused by Disposable Gloves. Environ. Sci. Technol. 2020, 54, 12164-12172. [CrossRef] [PubMed]

34. Ceccarini, A.; Corti, A.; Erba, F.; Modugno, F.; La Nasa, J.; Bianchi, S.; Castelvetro, V. The Hidden Microplastics: New Insights and Figures from the Thorough Separation and Characterization of Microplastics and of Their Degradation Byproducts in Coastal Sediments. Environ. Sci. Technol. 2018, 52, 5634-5643. [CrossRef] [PubMed]

35. Simmerman, C.B.; Coleman Wasik, J.K. The effect of urban point source contamination on microplastic levels in water and organisms in a cold-water stream. Limnol. Oceanogr. Lett. 2020, 5, 137-146. [CrossRef]

36. Dowarah, K.; Devipriya, S.P. Microplastic prevalence in the beaches of Puducherry, India and its correlation with fishing and tourism/recreational activities. Mar. Pollut. Bull. 2019, 148, 123-133. [CrossRef] [PubMed]

37. Silva, A.B.; Bastos, A.S.; Justino, C.I.L.; da Costa, J.P.; Duarte, A.C.; Rocha-Santos, T.A.P. Microplastics in the environment: Challenges in analytical chemistry-A review. Anal. Chim. Acta 2018, 1017, 1-19. [CrossRef]

38. Duemichen, E.; Eisentraut, P.; Celina, M.; Braun, U. Automated thermal extraction-desorption gas chromatography mass spectrometry: A multifunctional tool for comprehensive characterization of polymers and their degradation products. J. Chromatogr. A 2019, 1592, 133-142. [CrossRef]

39. Taghizadeh Rahmat Abadi, Z.; Abtahi, B.; Grossart, H.P.; Khodabandeh, S. Microplastic content of Kutum fish, Rutilus frisii kutum in the southern Caspian Sea. Sci. Total Environ. 2021, 752, 141542. [CrossRef] [PubMed]

40. Löder, M.G.J.; Gerdts, G. Methodology Used for the Detection and Identification of Microplastics-A Critical Appraisal. In Marine Anthropogenic Litter; Bergmann, M., Gutow, L., Klages, M., Eds.; Springer International Publishing: Cham, Switzerland, 2015; pp. 201-227.

41. Dehghani, S.; Moore, F.; Akhbarizadeh, R. Microplastic pollution in deposited urban dust, Tehran metropolis, Iran. Environ. Sci. Pollut. Res. Int. 2017, 24, 20360-20371. [CrossRef] [PubMed]

42. Hendrickson, E.; Minor, E.C.; Schreiner, K. Microplastic Abundance and Composition in Western Lake Superior As Determined via Microscopy, Pyr-GC/MS, and FTIR. Environ. Sci. Technol. 2018, 52, 1787-1796. [CrossRef] 
43. Shim, W.J.; Hong, S.H.; Eo, S.E. Identification methods in microplastic analysis: A review. Anal. Methods 2017, 9, 1384-1391. [CrossRef]

44. Tunali, M.; Uzoefuna, E.N.; Tunali, M.M.; Yenigun, O. Effect of microplastics and microplastic-metal combinations on growth and chlorophyll a concentration of Chlorella vulgaris. Sci. Total Environ. 2020, 743, 140479. [CrossRef] [PubMed]

45. Hossain, M.R.; Jiang, M.; Wei, Q.; Leff, L.G. Microplastic surface properties affect bacterial colonization in freshwater. J. Basic Microbiol. 2019, 59, 54-61. [CrossRef] [PubMed]

46. Sabri, N.H.; Muhammad, A.; Abdul Rahim, N.H.; Roslan, A.; Abu Talip, A.R. Feasibility study on co-pyrolyzation of microplastic extraction in conventional sewage sludge for the cementitious application. Mater. Today Proc. 2021, 46, 2112-2117. [CrossRef]

47. Mossotti, R.; Dalla Fontana, G.; Anceschi, A.; Gasparin, E.; Battistini, T. Preparation and analysis of standards containing microfilaments/microplastic with fibre shape. Chemosphere 2021, 270, 129410. [CrossRef]

48. Abbasi, S. Prevalence and physicochemical characteristics of microplastics in the sediment and water of Hashilan Wetland, a national heritage in NW Iran. Environ. Technol. Innov. 2021, 23, 101782. [CrossRef]

49. Avio, C.G.; Gorbi, S.; Regoli, F. Experimental development of a new protocol for extraction and characterization of microplastics in fish tissues: First observations in commercial species from Adriatic Sea. Mar. Environ. Res. 2015, 111, 18-26. [CrossRef] [PubMed]

50. Witkowski, H.; Koniorczyk, M. New sampling method to improve the reliability of FTIR analysis for Self-Compacting Concrete. Constr. Build. Mater. 2018, 172, 196-203. [CrossRef]

51. Jung, M.R.; Horgen, F.D.; Orski, S.V.; Rodriguez C, V.; Beers, K.L.; Balazs, G.H.; Jones, T.T.; Work, T.M.; Brignac, K.C.; Royer, S.-J.; et al. Validation of ATR FT-IR to identify polymers of plastic marine debris, including those ingested by marine organisms. Mar. Pollut. Bull. 2018, 127, 704-716. [CrossRef] [PubMed]

52. Veerasingam, S.; Ranjani, M.; Venkatachalapathy, R.; Bagaev, A.; Mukhanov, V.; Litvinyuk, D.; Mugilarasan, M.; Gurumoorthi, K.; Guganathan, L.; Aboobacker, V.M.; et al. Contributions of Fourier transform infrared spectroscopy in microplastic pollution research: A review. Crit. Rev. Environ. Sci. Technol. 2020, 1-63. [CrossRef]

53. Hebner, T.S.; Maurer-Jones, M.A. Characterizing microplastic size and morphology of photodegraded polymers placed in simulated moving water conditions. Environ. Sci. Process. Impacts 2020, 22, 398-407. [CrossRef] [PubMed]

54. Corami, F.; Rosso, B.; Bravo, B.; Gambaro, A.; Barbante, C. A novel method for purification, quantitative analysis and characterization of microplastic fibers using Micro-FTIR. Chemosphere 2020, 238, 124564. [CrossRef] [PubMed]

55. Mintenig, S.M.; Int-Veen, I.; Löder, M.G.J.; Primpke, S.; Gerdts, G. Identification of microplastic in effluents of waste water treatment plants using focal plane array-based micro-Fourier-transform infrared imaging. Water Res. 2017, 108, 365-372. [CrossRef]

56. Vianello, A. A Journey into Microplastic Analysis Using FTIR Spectroscopy. Ph.D. Thesis, Aalborg University, Aalborg, Denmark, 2020.

57. Olesen, K.; van Alst, N.; Simon, M.; Vianello, A.; Liu, F.; Vollertsen, J. Analysis of Microplastics using FTIR Imaging Application Note. Agil. Appl. Note Environ. 2017, 5991-8271EN. Available online: https://www.researchgate.net/publication/332083136_ Analysis_of_Microplastics_using_FTIR_Imaging_Application_Note (accessed on 25 September 2021).

58. Simon, M.; van Alst, N.; Vollertsen, J. Quantification of microplastic mass and removal rates at wastewater treatment plants applying Focal Plane Array (FPA)-based Fourier Transform Infrared (FT-IR) imaging. Water Res. 2018, 142, 1-9. [CrossRef] [PubMed]

59. Primpke, S.; Wirth, M.; Lorenz, C.; Gerdts, G. Reference database design for the automated analysis of microplastic samples based on Fourier transform infrared (FTIR) spectroscopy. Anal. Bioanal. Chem. 2018, 410, 5131-5141. [CrossRef] [PubMed]

60. Shahzad, I.; Wittchen, S.; Cepus, V. In Situ Migration Analysis and Diffusion Coefficient Determination of Bio-Based Plasticizer From NBR Using FTIR-ATR and Estimation of Migrated Plasticizer Contents by TGA Analysis. Macromol. Symp. 2019, 384, 1800158. [CrossRef]

61. Anger, P.M.; Prechtl, L.; Elsner, M.; Niessner, R.; Ivleva, N.P. Implementation of an open source algorithm for particle recognition and morphological characterisation for microplastic analysis by means of Raman microspectroscopy. Anal. Methods 2019, 11, 3483-3489. [CrossRef]

62. Müsellim, E.; Tahir, M.H.; Ahmad, M.S.; Ceylan, S. Thermokinetic and TG/DSC-FTIR study of pea waste biomass pyrolysis. Appl. Therm. Eng. 2018, 137, 54-61. [CrossRef]

63. Rodriguez Chialanza, M.; Sierra, I.; Perez Parada, A.; Fornaro, L. Identification and quantitation of semi-crystalline microplastics using image analysis and differential scanning calorimetry. Environ. Sci. Pollut. Res. Int. 2018, 25, 16767-16775. [CrossRef] [PubMed]

64. Bitter, H.; Lackner, S. Fast and easy quantification of semi-crystalline microplastics in exemplary environmental matrices by differential scanning calorimetry (DSC). Chem. Eng. J. 2021, 423, 129941. [CrossRef]

65. Ma, Z.; Wang, J.; Yang, Y.; Zhang, Y.; Zhao, C.; Yu, Y.; Wang, S. Comparison of the thermal degradation behaviors and kinetics of palm oil waste under nitrogen and air atmosphere in TGA-FTIR with a complementary use of model-free and model-fitting approaches. J. Anal. Appl. Pyrolysis 2018, 134, 12-24. [CrossRef]

66. Majewsky, M.; Bitter, H.; Eiche, E.; Horn, H. Determination of microplastic polyethylene (PE) and polypropylene (PP) in environmental samples using thermal analysis (TGA-DSC). Sci. Total Environ. 2016, 568, 507-511. [CrossRef]

67. Sun, J.; Dai, X.; Wang, Q.; van Loosdrecht, M.C.M.; Ni, B.J. Microplastics in wastewater treatment plants: Detection, occurrence and removal. Water Res. 2019, 152, 21-37. [CrossRef]

68. Dumichen, E.; Eisentraut, P.; Bannick, C.G.; Barthel, A.K.; Senz, R.; Braun, U. Fast identification of microplastics in complex environmental samples by a thermal degradation method. Chemosphere 2017, 174, 572-584. [CrossRef] 
69. Okoffo, E.D.; O'Brien, S.; O’Brien, J.W.; Tscharke, B.J.; Thomas, K.V. Wastewater treatment plants as a source of plastics in the environment: A review of occurrence, methods for identification, quantification and fate. Environ. Sci. Water Res. Technol. 2019, 5, 1908-1931. [CrossRef]

70. Wang, W.; Ge, J.; Yu, X.; Li, H. Environmental fate and impacts of microplastics in soil ecosystems: Progress and perspective. Sci. Total Environ. 2020, 708, 134841. [CrossRef]

71. Luo, H.; Xiang, Y.; Li, Y.; Zhao, Y.; Pan, X. Photocatalytic aging process of Nano-TiO2 coated polypropylene microplastics: Combining atomic force microscopy and infrared spectroscopy (AFM-IR) for nanoscale chemical characterization. J. Hazard Mater. 2021, 404, 124159. [CrossRef]

72. Luo, H.; Xiang, Y.; Zhao, Y.; Li, Y.; Pan, X. Nanoscale infrared, thermal and mechanical properties of aged microplastics revealed by an atomic force microscopy coupled with infrared spectroscopy (AFM-IR) technique. Sci. Total Environ. 2020, 744, 140944. [CrossRef]

73. Prata, J.C.; da Costa, J.P.; Duarte, A.C.; Rocha-Santos, T. Methods for sampling and detection of microplastics in water and sediment: A critical review. TrAC Trends Anal. Chem. 2019, 110, 150-159. [CrossRef]

74. Sancataldo, G.; Avellone, G.; Vetri, V. Nile Red lifetime reveals microplastic identity. Environ. Sci. Process Impacts 2020, 22, 2266-2275. [CrossRef] [PubMed]

75. Vermeiren, P.; Munoz, C.; Ikejima, K. Microplastic identification and quantification from organic rich sediments: A validated laboratory protocol. Environ. Pollut. 2020, 262, 114298. [CrossRef]

76. Al-Azzawi, M.S.M.; Kefer, S.; Weißer, J.; Reichel, J.; Schwaller, C.; Glas, K.; Knoop, O.; Drewes, J.E. Validation of Sample Preparation Methods for Microplastic Analysis in Wastewater Matrices-Reproducibility and Standardization. Water 2020, 12, 2445. [CrossRef]

77. Li, X.; Chen, L.; Ji, Y.; Li, M.; Dong, B.; Qian, G.; Zhou, J.; Dai, X. Effects of chemical pretreatments on microplastic extraction in sewage sludge and their physicochemical characteristics. Water Res. 2020, 171, 115379. [CrossRef]

78. Zhang, J.; Tian, K.; Lei, C.; Min, S. Identification and quantification of microplastics in table sea salts using micro-NIR imaging methods. Anal. Methods 2018, 10, 2881-2887. [CrossRef]

79. Paul, A.; Wander, L.; Becker, R.; Goedecke, C.; Braun, U. High-throughput NIR spectroscopic (NIRS) detection of microplastics in soil. Environ. Sci. Pollut. Res. Int. 2019, 26, 7364-7374. [CrossRef]

80. Corradini, F.; Bartholomeus, H.; Huerta Lwanga, E.; Gertsen, H.; Geissen, V. Predicting soil microplastic concentration using vis-NIR spectroscopy. Sci. Total Environ. 2019, 650, 922-932. [CrossRef] [PubMed]

81. Luo, H.; Zeng, Y.; Zhao, Y.; Xiang, Y.; Li, Y.; Pan, X. Effects of advanced oxidation processes on leachates and properties of microplastics. J. Hazard Mater. 2021, 413, 125342. [CrossRef]

82. Guen, E.; Klapetek, P.; Puttock, R.; Hay, B.; Allard, A.; Maxwell, T.; Chapuis, P.-O.; Renahy, D.; Davee, G.; Valtr, M.; et al. SThM-based local thermomechanical analysis: Measurement intercomparison and uncertainty analysis. Int. J. Therm. Sci. 2020, 156, 106502. [CrossRef]

83. Savoca, S.; Capillo, G.; Mancuso, M.; Faggio, C.; Panarello, G.; Crupi, R.; Bonsignore, M.; D’Urso, L.; Compagnini, G.; Neri, F.; et al. Detection of artificial cellulose microfibers in Boops boops from the northern coasts of Sicily (Central Mediterranean). Sci. Total Environ. 2019, 691, 455-465. [CrossRef] [PubMed]

84. Henry, B.; Laitala, K.; Klepp, I.G. Microfibres from apparel and home textiles: Prospects for including microplastics in environmental sustainability assessment. Sci. Total Environ. 2019, 652, 483-494. [CrossRef] [PubMed]

85. Gago, J.; Carretero, O.; Filgueiras, A.V.; Vinas, L. Synthetic microfibers in the marine environment: A review on their occurrence in seawater and sediments. Mar. Pollut. Bull. 2018, 127, 365-376. [CrossRef] [PubMed]

86. Barrows, A.P.W.; Cathey, S.E.; Petersen, C.W. Marine environment microfiber contamination: Global patterns and the diversity of microparticle origins. Environ. Pollut. 2018, 237, 275-284. [CrossRef] [PubMed] 